was also used. In order to confirm the specificity of the new genetic variation associated with PsA risk, we analyzed the association with purely cutaneous psoriasis (PsC, $n=614$ ) and rheumatoid arthritis (RA, $n=1,191)$. We performed a pharmacogenetic analysis to investigate the new PsA-specific pathways as a source for drug discovery in PsA.

Results: GWAS meta-analysis identified a new association between B3GNT2 gene and PsA $(P<5 \mathrm{e}-08)$. In the GWAS pathway analysis, we identified and validated a total of 14 genetic pathways associated with PsA risk. From these, the glycosaminoglycan (GAG) metabolism pathway was also found to be significantly associated with PsA risk when directly contrasted to the PsC cohort as well as the RA cohort. At the functional level, we detected a significant differential expression of GAG metabolism pathway genes in blood samples from PsA patients compared to PsC patients. The pharmacogenetic analysis identified several FDA-approved drugs likely to modify the GAG pathway.

Conclusions: The present study represents an important step towards the characterization of the genetic factors specific to PsA risk.

Disclosure of Interest: None declared

DOI: 10.1136/annrheumdis-2017-eular.3685

\section{SAT0459 LOW DOSE IL-2 RESTORES IMBALANCE BETWEEN TH17 AND REGULATORY T CELLS IN PATIENTS WITH PSORIATIC ARTHRITIS}

K. Qin ${ }^{1}$, Q. Chen ${ }^{1}$, J. Fan ${ }^{1}$, D. Xu ${ }^{1}$, X. Li ${ }^{1}$, C. Wang ${ }^{1}$, C. Gao ${ }^{2} .{ }^{1}$ Rheumatology, the Second Hospital of Shanxi Medical University, Taiyuan, China; ${ }^{2}$ Pathology, Joint Program in Transfusion Medicine, Brigham and Women's Hospital/Children's Hospital Boston, Harvard Medical School, Boston, United States

Background: Psoriasis arthritis is one of chronic, relapsing, inflammatory autoimmune disorders with skin lesions and joint damage. A therapeutic revolution of psoriatic arthritis (PsA) is still a considerable unmet need in the past decades. It has been well known that the imbalance of Th17 cells and regulatory T cells (Tregs) may be a pivotal cause of PsA. Correction of this dysfunction can be a potential therapy of PsA.

Objectives: In this study, we measured and compared both absolute numbers and proportions of CD4+CD17+ Th17 cells and CD4+CD25+Foxp3+ Treg cells in peripheral blood of PsA patients and healthy controls to explore the immunopathogenesis of PsA; on the other hand, the effects of low-dose recombinant human IL-2 (rhIL-2) on Th17 and Treg cells were investigated in patients with PsA.

Methods: Both absolute numbers and proportions of Treg and Th17 cells in peripheral blood, defined as the CD4+CD25+Foxp3+T or CD4+IL-17+ T cell populations, were examined by flow cytometry in 40 healthy controls and 77 patients with PsA, including 39 patients who had never received diseasemodifying antirheumatic drugs (DMARDs) and 38 patients who were receiving or had received DMARDs. Among these patients, 20 patients consented at enrollment to receive $\mathrm{rhlL}-2$ treatment. Before and after treatment $(50 \mathrm{WIU} / \mathrm{d}$ for 5 days, $I H)$, Th17 and Treg cells in peripheral blood were analyzed by flow cytometry.

Results: The absolute count of Th17 cells in patients with PsA was very significantly higher than that of healthy controls $(P<0.01)$, but the proportions of Th17 cell were not seen difference between PsA and healthy controls $(P>0.05)$. In contrast with treated-PsA patients, the absolute count of Th17 cells was significant higher in untreated-PsA patients $(P<0.05)$. After the course of rhIL-2 treatment, there was a significant increase in the absolute count of Treg cells $(P<0.05)$, but no diference in the absolute count of Th17 cells, Th17/Treg was significantly lower and went back to nomal.

Conclusions: The results suggest that, not the proportion, but the decrease in the absolute count of Th17 cells, defined as the CD4+CD17+ populations, contributes to the pathogenesis of PsA. After the treatment of rhIL-2, there was a more significant increase in the absolute count of Treg cells than that of Th17, and consequently the balance of Th17/Treg was restored to normal, leading to the development of new therapies.

References:

[1] Karczewski J, Dobrowolska A, Rychlewskahańczewska A, et al. New insights into the role of $\mathrm{T}$ cells in pathogenesis of psoriasis and psoriatic arthritis[J]. Autoimmunity, 2016:1.DOI:10.3109/08916934.2016.1166214.

[2] Yoo I S, Lee J H, Song S T, et al. T-helper 17 cells: the driving force of psoriasis and psoriatic arthritis.[J]. International Journal of Rheumatic Diseases, 2012, 15(6):531-537. DOI:10.1111/j.1756-185X.2012.01813.x.

[3] Szodoray P, Nakken B, Barath S, et al. Altered Th17 cells and Th17/regulatory T-cell ratios indicate the subsequent conversion from undifferentiated connective tissue disease to definitive systemic autoimmune disorders[J]. Human Immunology, 2013, 74(12):1510-8. DOI:10.1016/..humimm.2013.08.003.

[4] Raychaudhuri S P. Role of IL-17 in psoriasis and psoriatic arthritis.[J]. Clinical Reviews in Allergy \& Immunology, 2013, 44(2):183-193. DOI: 10.1007/s12016-012-8307-1.

Disclosure of Interest: None declared

DOI: 10.1136/annrheumdis-2017-eular.6027

\section{SAT0460 ASSOCIATION BETWEEN INFLAMMASOME-RELATED POLYMORPHISMS AND PSORIATIC ARTHRITIS}

K. Juneblad ${ }^{1}$, A. Kastbom ${ }^{2}$, S. Rantapää-Dahlqvist ${ }^{1}$, P. Söderkvist ${ }^{3}$, G.-M. Alenius ${ }^{1} .{ }^{1}$ Dept of Public Health and Clinical Medicine/Rheumatology, University Hospital, Umeå, Umeå; ${ }^{2}$ Department of Clinical and Experimental Medicine, Rheumatology; ${ }^{3}$ Division of Cell Biology, Dept of Clinical and Experimental medicine, Linköping University, Linköping, Sweden

Background: In recent years, research on the interleukin 1 $\beta$ (IL1 $\beta)$-regulating protein complex, called the inflammasome, has shown interesting associations with various inflammatory diseases. E.g. for Rheumatoid Arthritis (RA) (1) and psoriasis (Pso) $(2,3)$ associations with genetic polymorphisms in genes related to the inflammasome has been discovered. So far, no studies investigating genetic polymorphisms in inflammasome genes in Psoriatic Arthritis (PsA) patients have been published.

Objectives: To examine whether polymorphisms in genes related to inflammasomes confer increased risk for psoriatic arthritis.

Methods: DNA from 771 PsA patients and 793 healthy controls from Sweden were analyzed for different single nucleotide polymorphisms (SNPs) in NLRP3 (rs35829419, rs 10733113, rs4353135), CARD8 (rs 2043211) and NLRP1 (rs8079034, rs878329).

Results: Significant associations with PsA were found between carriage of allele, $\mathrm{C}$, of rs878329 in NLRP1 (Chi-2=6.5, OR (95\% Cl); $0.75(0.60-0.94), \mathrm{P}=0.011)$ and allele $\mathrm{G}$ in rs4353135 in NLRP3 (Chi-2=4.8, OR (95\% Cl); 1.25 (1.02-1.53), $\mathrm{p}=0.028$ ). Genotype distribution were also significantly different between patients and controls and for rs878329 in NLRP1 there was a significant difference in allele frequency $(\mathrm{G} / \mathrm{C})$ between patients and controls (Chi-2 $=5.8$, OR $(95 \% \mathrm{Cl})$; 1.20 (1.03-1.38), $p=0.016$ ). No significant associations with PsA were found for the other SNPs analyzed.

In genotype analysis, a significant higher frequency of genotype GG in rs878329 in PsA was detected (32.9\% vs 26.9\%, Chi-2=6.49, OR (95\% Cl); 1.34 (1.07-1.67), $\mathrm{p}=0.011$ ), whilst no significant differences were detected for genotypes $G C$ or CC. For rs 4353135 , a significantly higher frequency of genotype TG $(43 \%$ vs $37.6 \%$, Chi-2=4.66, OR (95\% Cl); $1.25(1.02-1.53), \mathrm{P}=0.033)$ and a significantly lower frequency of genotype TT ( $50.5 \%$ vs $56.1 \%$, Chi- $2=4.85$, OR $(95 \% \mathrm{Cl}) ; 0.80$ $(0.65-0.98), P=0.028)$ was seen in PsA, no significan difference was detected for genotype GG.

Conclusions: Carriage of rs $878329 \mathrm{C}$ in NLRP1 was less frequent in patients with PsA compared with controls indicating a protecting effect, but when different genotypes were analysed the difference likely results from an increased risk of PsA with genotype GG. The results are in contrast with the study of Ekman et al, where an increased transmission of rs $878329 \mathrm{C}$ to family members with psoriasis was seen (3), indicating an increased risk of developing skin psoriasis for carriers of $\mathrm{C}$, but in agreement with the study of Sui et al on patients with $R A$, where an association was detected for carriage of $C$ (OR $0.82, p=0.02)$, with the risk genotype for RA being GG (4). Thus, the genotype GG possibly confers risk of arthritic disease whilst the $\mathrm{C}$-allele seems associated with skin disease. Carriage of rs $4353135 \mathrm{G}$ in NLRP3 was more frequent in PsA patients compared with controls indicating an increased risk of disease, but only genotype GT was significantly increased in PsA. The study is, to our knowledge, the first to study possible associations between genes related to the inflammasome and PsA. In the study associations were found between one SNP in NLRP3 and one SNP in $N L R P 1$, indicating a possible involvement in pathogenesis of PsA disease.

\section{References:}

[1] Rheumatol 2008:47:415-7.

[2] Exp Dermatol 2012;21:932-7.

[3] Br J Rheumatol 2014;171:1517-20.

[4] Arthritis Rheum 2012;64:647-54.

Disclosure of Interest: None declared

DOI: 10.1136/annrheumdis-2017-eular.3477

\section{SAT0461 CHARACTERISATION OF DIFFERENT LOW DISEASE ACTIVITY MEASUREMENTS IN PATIENTS WITH PSORIATIC ARTHRITIS}

L.C. Coates ${ }^{1}$, A.B. Gottlieb ${ }^{2}$, J.F. Merola ${ }^{3}$, L. Aikman ${ }^{4}$, A. Szumski ${ }^{5}$,

A. Chhabra ${ }^{6} .{ }^{1}$ University of Leeds, Leeds, United Kingdom; ${ }^{2}$ New York Medical College, New York; ${ }^{3}$ Harvard Medical School, Boston, United States; ${ }^{4}$ Pfizer, Walton Oaks, United Kingdom; ${ }^{5}$ InVentiv Health, Princeton; ${ }^{6}$ Pfizer, New York, United States

Background: Selection of the correct target to guide treatment is crucial for effective disease management in patients with psoriatic arthritis (PsA).

Objectives: To evaluate the prognostic value of several low disease activity (LDA) measurements in patients with PSA and psoriasis to assist physicians choose a valid target that facilitates assessment in clinical practice.

Methods: This was a post-hoc analysis from the PRESTA ${ }^{1}$ clinical study. LDA targets analyzed were: Disease Activity in PsA (DAPSA) LDA $\leq 14$ (tender joint count [TJC], swollen joint count [SJC], patient global visual analog scale [Pt VAS], pain VAS, C-reactive protein [CRP]; clinical (c)DAPSA LDA $\leq 13$ (DAPSA without CRP); and minimal disease activity (MDA) measurement defined as $5 / 7$ cut-offs (TJC $\leq 1$, SJC $\leq 1$, psoriasis activity and severity index [PASI] $\leq 1, \mathrm{Pt}$ pain $\leq 15 \mathrm{~mm}$, Pt VAS $\leq 20 \mathrm{~mm}$, health assessment questionnaire $\leq 0.5$, tender entheseal points $\leq 1$ ). Additional MDA measurements were investigated where $5 / 7$ 
Abstract SAT0461 - Table 1. Proportion of patients with residual disease at Week 24

\begin{tabular}{|c|c|c|c|c|c|c|}
\hline & MDA 5/7, n/N (\%) & MDA_skin, n/N (\%) & MDA_joint, n/N (\%) & MDA_joint + skin, n/N (\%) & DAPSA LDA, n/N (\%) & cDAPSA LDA, n/N (\%) \\
\hline Dactylitis (1-12) & 10/322 (3) & $6 / 131(5)$ & $5 / 255(2)$ & $3 / 97(3)$ & $18 / 475$ (4) & $17 / 478(4)$ \\
\hline Enthesitis $(1-5)$ & $2 / 324(1)$ & 2/132 (2) & $1 / 256(0)$ & $1 / 97(1)$ & $16 / 477$ (3) & $16 / 480(3)$ \\
\hline PASI (2-9) & $142 / 324(44)$ & $0 / 132(0)$ & $119 / 256(47)$ & $0 / 97(0)$ & $237 / 477(50)$ & $237 / 480$ (49) \\
\hline PASI $(\geq 10)$ & $17 / 324(5)$ & $0 / 132(0)$ & $14 / 256(6)$ & $0 / 97(0)$ & r 38/477 (8) & $39 / 480(8)$ \\
\hline $\operatorname{TJC}(>1)$ & $46 / 324(14)$ & $28 / 132(21)$ & $0 / 256(0)$ & $0 / 97(0)$ & $140 / 477(29)$ & $139 / 480(29)$ \\
\hline SJC $(>1)$ & $25 / 324(8)$ & $15 / 132(11)$ & $0 / 256(0)$ & $0 / 97(0)$ & $65 / 477$ (14) & $65 / 480(14)$ \\
\hline
\end{tabular}

cut-offs were met but some were mandated: MDA_joint with both TJC and SJC cut-offs mandated, MDA_skin where PASI cut-off was mandated, MDA_joint+skin where the TJC, SJC, and skin cut-offs were mandated.

Results: At Week 24, the proportion of patients achieving LDA were $47 \%, 20 \%$, $38 \%, 14 \%$ in MDA 5/7, MDA skin, MDA joint, MDA joint+skin, respectively, vs $\sim 71 \%$ in DAPSA and cDAPSA LDA. The highest proportion of discordance was observed between MDA_skin or MDA_joint+skin with DAPSA LDA or cDAPSA LDA (Figure). The majority of patients had no residual arthritis although levels were highest in the DAPSA measurements (Table). However, notable residual levels of psoriasis were observed in measurements that did not require skin disease control (Table 1). MDA joint+skin had the lowest levels of residual disease across all cut-offs (Table 1$)$. At Week 12, a significant difference $(P<0.05)$ between the $50 \mathrm{mg}$ etanercept (ETN) once a week and $50 \mathrm{mg}$ ETN twice a week cohorts was observed in the measurements that required a skin cut-off (MDA skin and MDA joint+skin) and MDA 5/7 but not in DAPSA LDA, CDAPSA LDA, or MDA joint.

Figure. Proportion with discordance for DAPSA LDA or CDAPSA LDA across different low disease activity definitions at Week 24

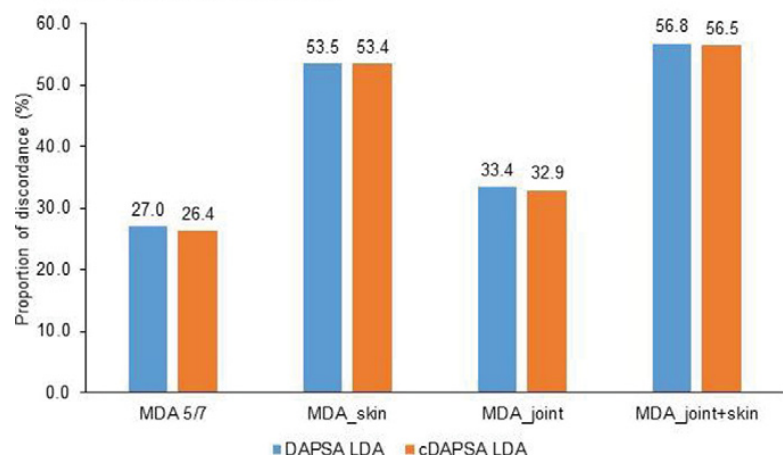

Conclusions: DAPSA and CDAPSA LDA provided the least stringent cut-offs with the highest percentages of patients with residual disease. Whilst choosing the optimal target for treatment requires more debate, it is clear from these data that levels of residual psoriasis are high in those measurements that do not require skin control. If this is not included in a treatment target for PsA, notable levels of psoriasis can be missed.

References:

[1] Sterry W, et al. BMJ 2010;340:c1471.

Disclosure of Interest: L. Coates Grant/research support from: Abbvie, Janssen, Consultant for: Abbvie, BMS, Janssen, Lilly, MSD, Novartis, Pfizer, A. Gottlieb Grant/research support from: Centocor (Janssen), Amgen, Abbvie, Novartis, Celgene, Pfizer, Lilly, Levia, Merck, Xenoport, Dermira, Baxalta, Consultant for: Amgen, Astellas, Akros, Centocor (Janssen), Celgene, Bristol Myers Squibb, Beiersdorf, Abbvie, TEVA, Actelion, UCB, Novo Nordisk, Novartis, Dermipsor, Incyte, Pfizer, Canfite, Lilly, Coronado, Vertex, Karyopharm, CSL Behring Biotherapies for Life, Glaxo Smith Kline, Xenoport, Catabasis, Meiji Seika Pharma, Takeda, Mitsubishi,Tanabe Pharma Development America, Genentech, Baxalta, Kineta One, KPI Therapeutics, Crescendo Bioscience, Aclaris, Amicus, Reddy Labs, Speakers bureau: Abbvie, J. Merola Consultant for: Biogen IDEC, AbbVie, Amgen, Eli Lilly, Novartis, Pfizer, Janssen, UCB, Kiniksa, Momenta and Mallinckrodt, L. Aikman Shareholder of: Pfizer, Employee of: Pfizer, A. Szumski Employee of: InVentiv Health, A. Chhabra Shareholder of: Pfizer, Employee of: Pfizer DOI: 10.1136/annrheumdis-2017-eular.1874

\section{SAT0462 SECUKINUMAB PROVIDES SUSTAINED PASDAS RELATED LOW DISEASE ACTIVITY IN PSORIATIC ARTHRITIS: 2 YEAR RESULTS FROM THE FUTURE 2 STUDY}

L.C. Coates ${ }^{1,2}$, D.D. Gladman ${ }^{3}$, P. Nash ${ }^{4}$, O. Fitzgerald ${ }^{5}$, A. Kavanaugh ${ }^{6}$, L. Rasouliyan ${ }^{7}$, L. Pricorp ${ }^{8}$, K. Ding ${ }^{8}$, C. Gaillez ${ }^{9}$ on behalf of the FUTURE 2 study group. ${ }^{1}$ Leeds Teaching Hospitals NHS Trust; ${ }^{2}$ University of Leeds, Leeds, United Kingdom; ${ }^{3}$ Toronto western hospital, Toronto, Canada; ${ }^{4}$ University of Queensland, Brisbane, Australia; ${ }^{5}$ University College Dublin, Dublin, Ireland; ${ }^{6}$ UC San Diego School of Medicine, la Jolla, United States: ${ }^{7}$ RTI Health Solutions, Barcelona, Spain; ${ }^{8}$ Novartis Pharmaceuticals Corporation, East Hanover, United States; ${ }^{9}$ Novartis Pharma AG, Basel, Switzerland

Background: Psoriatic arthritis (PsA) disease activity score (PASDAS) assessing multiple facets of PsA was demonstrated to distinguish treatment effect, perform better in statistical terms than traditional joint-only indices ${ }^{1}$ and could be used as a treatment target in clinical trials in PsA.

Objectives: Secukinumab provided sustained improvement in the signs and symptoms of PsA over 104 weeks (wks) in the FUTURE 2 study. ${ }^{2}$ Here, we report the ability of secukinumab to reach and sustain PASDAS based low disease activity (LDA) up to 104 wks in the FUTURE 2 study using a post-hoc exploratory analysis.

Methods: 397 patients (pts) with active PsA were randomised to subcutaneous (s.c.) secukinumab (300mg, 150mg, or $75 \mathrm{mg}$ ) or placebo (PBO) at baseline (BL) Wks 1,2 , and 3 , and every 4 wks $(q 4 w)$ from Wk 4 . PBO nonresponder and responder pts were re-randomised to secukinumab 300 or $150 \mathrm{mg}$ s.c. q4w from Wk 16 and 24, respectively. PASDAS is derived from physician's global VAS, patient's global VAS, SF-36 PCS, tender and swollen joints (TJC 68 and SJC 66), Leeds enthesitis count, dactylitis count and CRP level and has cut-points for high disease activity $(H D A \geq 5.4)$, low disease activity $(\operatorname{LAA}<3.2)$ and remission $(\mathrm{REM}<1.9) .^{3}$ PASDAS was assessed in the overall population and in pts stratified by prior anti-TNF use (naïve/inadequate response [IR]) and disease duration ( $\leq 2$ years vs. $>2$ years since diagnosis) and reported using non-mutually exclusive categories at group level and as observed analysis. Secukinumab $75 \mathrm{mg}$ data are not reported as this was not considered an effective dose. ${ }^{2}$

Results: PASDAS score (mean [SD]) at baseline was $5.9(0.9), 6.0$ (1.0) and 5.8 (1.0) in the secukinumab $300 \mathrm{mg}, 150 \mathrm{mg}$ and PBO groups. In the overall population at Wk 16, PASDAS LDA was achieved in $37 / 96$ (38.5\%) and 34/99 $(34.3 \%)$ of pts, treated with secukinumab $300 \mathrm{mg}$ and $150 \mathrm{mg}$, respectively; vs. $14 / 87(16.1 \%)$ with PBO. A high proportion of pts treated with secukinumab 300 and $150 \mathrm{mg}$ achieved LDA (49/83 [59.0\%] and 38/77 [49.4\%], respectively) at Wk 104. The proportion of pts achieving PASDAS LDA and remaining in HDA at Wks 16 and 104 by anti-TNF $\alpha$ status and by disease duration ( $\leq 2$ years vs. $>2$ years) for secukinumab 300 and $150 \mathrm{mg}$ is reported in the figure.
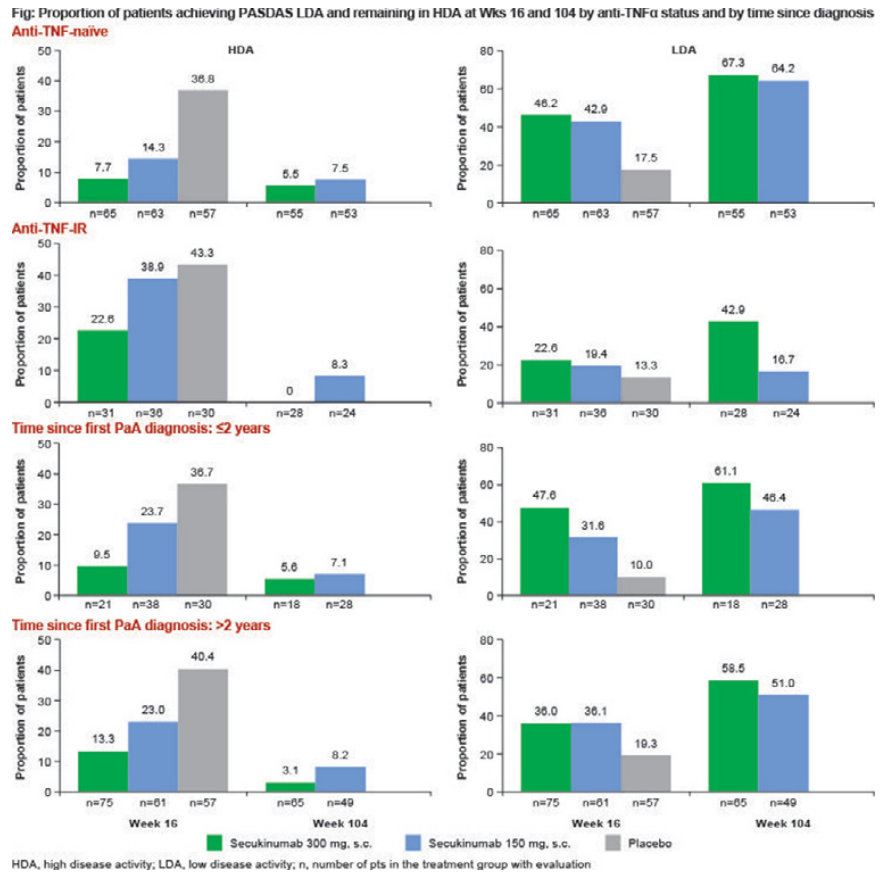

Conclusions: A higher proportion of secukinumab-treated pts at Wk 16 achieved PASDAS LDA than PBO, with LDA sustained at group level at Wk 104. Discriminatory effect of PASDAS was consistent with that previously reported in the GRACE project. ${ }^{4}$ A higher proportion of anti-TNF $\alpha$-naïve pts treated with secukinumab achieved and sustained PASDAS LDA than anti-TNF $\alpha$-IR pts whereas similar proportion of pts treated with secukinumab achieved PASDAS LDA irrespective of time since diagnosis ( $\leq 2$ years vs. $>2$ years).

References:

[1] Helliwell PS and Kavanaugh A. Arth Care and Res. 2014;66:749-56.

[2] McInnes IB et al, Arthritis Rheumatol. 2016;68 (suppl 10).

[3] Coates LC and Helliwell PS, J Rheumatol. 2016;43:371-5. 